\title{
Cost-benefit analysis method for building solutions
}

\author{
Catarina Araújo*, Manuela Almeida, Luís Bragança, José Amarilio Barbosa \\ University of Minho, Department of Civil Engineering C-TAC, 4800-058 Guimarães, Portugal
}

\section{H I G H L I G H T S}

- A new cost-benefit method was developed to compare building solutions.

- The method considers energy performance, life cycle costs and investment willingness.

- The graphical analysis helps stakeholders to easily compare building solutions.

- The method was applied to a case study showing consistency and feasibility.

\section{A R T I C L E I N F O}

\section{Article history:}

Received 27 November 2015

Received in revised form 29 February 2016

Accepted 6 April 2016

Available online 12 April 2016

\section{Keywords:}

Energy efficiency

Cost-benefit analysis

Investment willingness

\begin{abstract}
A B S T R A C T
The building sector is responsible for consuming approximately $40 \%$ of the final energy in Europe. However, more than $50 \%$ of this consumption can be reduced through energy-efficient measures. Our society is facing not only a severe and unprecedented environmental crisis but also an economic crisis of similar magnitude. In light of this, EU has developed legislation promoting the use of the CostOptimal (CO) method in order to improve building energy efficiency, in which selection criteria is based on life cycle costs. Nevertheless, studies show that the implementation of energy-efficient solutions is far from ideal. Therefore, it is very important to analyse the reasons for this gap between theory and implementation as well as improve selection methods. This study aims to develop a methodology based on a cost-effectiveness analysis, which can be seen as an improvement to the CO method as it considers the investment willingness of stakeholders in the selection process of energy-efficient solutions. The method uses a simple graphical display in which the stakeholders' investment willingness is identified as the slope of a reference line, allowing easy selection between building solutions. This method will lead to the selection of more desired - from stakeholders' point of view - and more energy-efficient solutions than those selected through the CO method.
\end{abstract}

(c) 2016 Elsevier Ltd. All rights reserved.

\section{Contents}

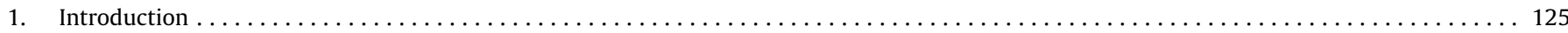

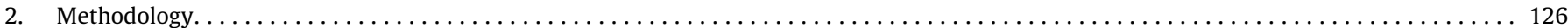

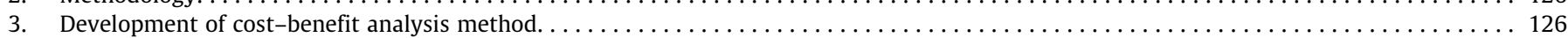

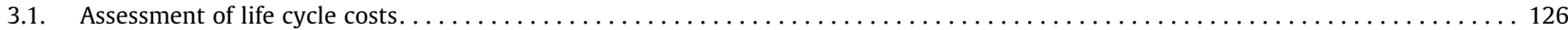

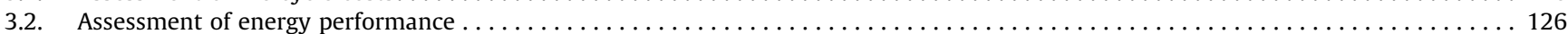

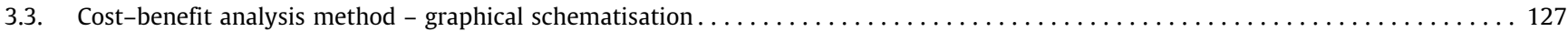

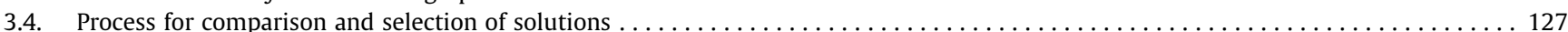

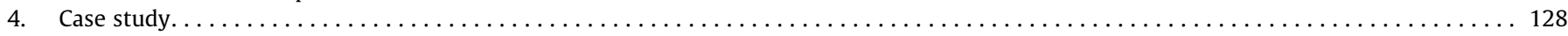

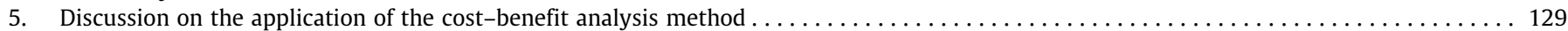

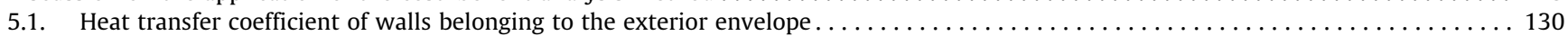

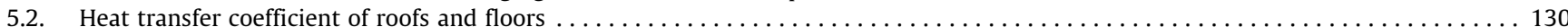

Abbreviations: EPBD, EU-Energy Performance of Buildings Directive; EU, European Union; CO, Cost-Optimal; CBA, Cost benefit analysis; DHW, Domestic Hot Water; LCC, Life Cycle Costs.

* Corresponding author.

E-mail addresses: cba@civil.uminho.pt (C. Araújo), malmeida@civil.uminho.pt (M. Almeida), braganca@civil.uminho.pt (L. Bragança), jabarbosa@civil.uminho.pt (J.A. Barbosa). 


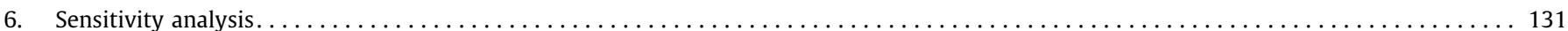

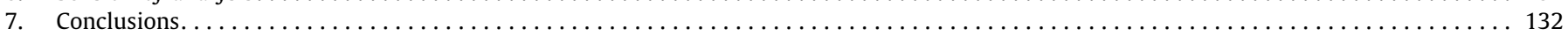

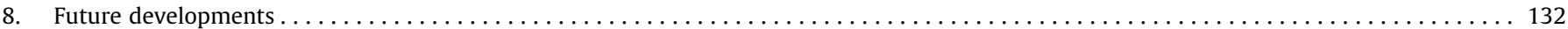

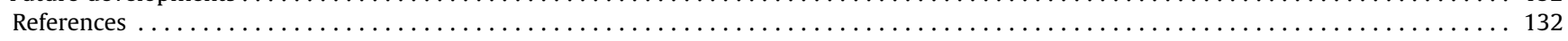

\section{Introduction}

One of the main contributors to the world's severe environmental crisis is energy production and usage. In the EU-27, 80\% of total GHG emissions are energy related [1]. In 2007 the Intergovernmental Panel on Climate Change (IPCC) [2] stated that the biggest portion of growth in carbon emissions was related to the buildings' operation. The building sector is responsible for consuming approximately $32 \%$ of the final energy and almost $40 \%$ of primary energy in Europe [3]. In many countries energy is also an important issue due to their high dependency on fossil fuel imports. Moreover, in 2013 more than half (53.2\%) of the EU-28's gross inland energy consumption came from imported sources [4]. One obvious way to solve Europe's energy problems is to reduce energy consumption [5]. This can be achieved through building energyefficient measures [6,7].

In order to deal with these issues and to accomplish the European climate and energy targets for 2020 [8], 2030 [9] and 2050 [10], substantial changes must be applied within the building sector. The Directive 2002/91/EC on Energy Performance of Buildings (EPBD) and its recast, the Directive 2010/31/EU, are currently the most important policies $[3,11]$. They aim to improve buildings' energy performance. In order to fulfil the requirements of these directives, several energy-efficient measures are to be applied both in new buildings and in retrofitting operations. In order to evaluate the energy and economic performance of building elements, the EPBD recast [3] has been imposed on EU Member States to implement a comparative methodology for calculating Cost-Optimal (CO) levels of minimum energy performance requirements for buildings and building elements [3]. The framework for the $\mathrm{CO}$ methodology has been published in the delegated regulation 244/2012 [12].

The CO method defines a reference scenario, representing the local building market, and compares several alternative building solutions based on their primary energy demand and Life Cycle Costs (LCC). The solutions are graphically represented, based on these parameters. This methodology assumes that the solutions (presented as dots) will draw a typical U-shaped curve, as shown in Fig. 1. The less expensive solution is therefore easily identified at the bottom. The selection process of the $\mathrm{CO}$ method indicates the $\mathrm{CO}$ building solution as the one leading to the lowest estimated LCC [12].

The selection criteria for EU's CO method focuses on the lowest LCC solution, and therefore prioritised over energy performance. This is because the development of the $\mathrm{CO}$ method was in alignment with policy makers needs and not with building investors or users' interests. This method was developed to be applied in the macro economy and aims to support the definition of reference values for CO solutions in EU Countries. In cases where stakeholders are less concerned with economic performance or more aware of environmental problems, this methodology can unnecessarily lead to higher energy consumption. In these cases it is necessary to develop and apply methods specifically developed to be used by small investors in a micro economy context.

Congedo et al. [14] and Baglivo et al. [15] applied the CO method to identify cost-optimal levels in new residential buildings located in a warm climate. The results showed that there is a gap between the $\mathrm{CO}$ solution and the energy-optimal solution, suggesting that this aspect should be thoroughly analysed. Becchio et al. [16] and Pikas et al. [17] reached the same conclusions. Due to

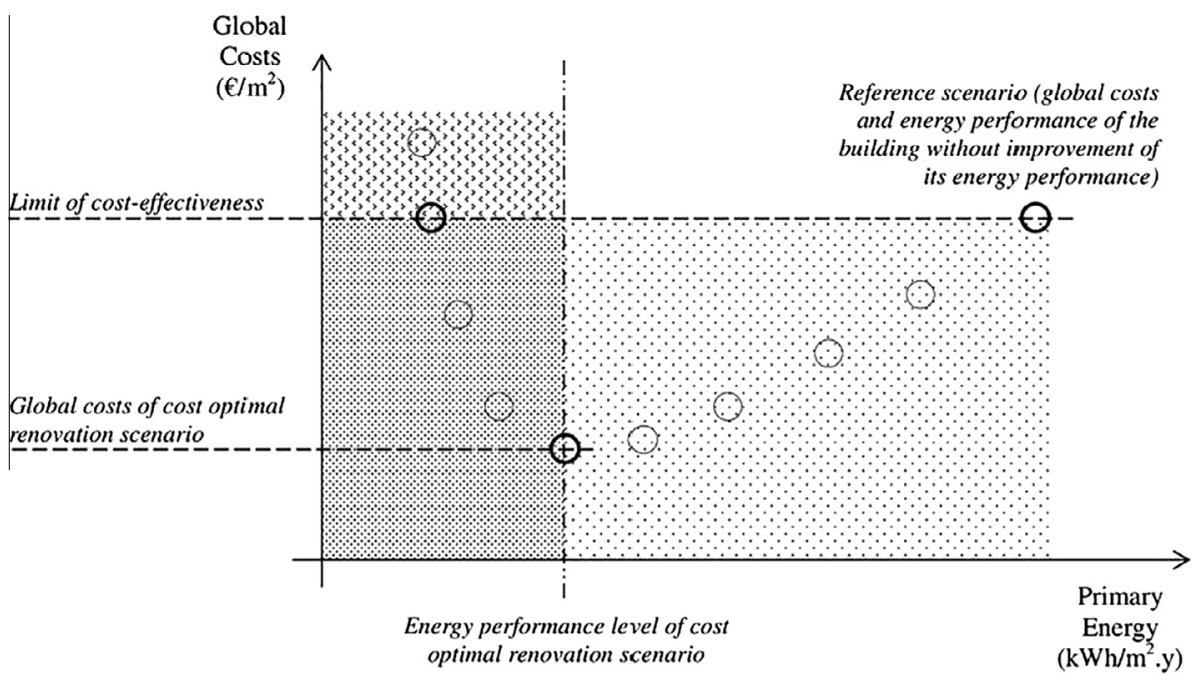

Renovation scenarios improving energy performance and reducing global costs

Renovation scenarios improving energy performance beyond cost optimal still being cost effective

Renovation scenarios improving energy performance but not cost effective

Fig. 1. Graphical representation of the Cost-Optimal method [13]. 
the urgent need to reduce energy consumption in buildings, the selection should fall on more efficient solutions that can still be profitable. Building retrofitting solutions should be seen as a way to not only decrease costs but also improve environmental performance. Furthermore, the implementation of energy-efficient measures is still far away from ideal and there is still a considerable energy saving potential in this sector $[18,19]$.

Several studies have been conducted in order to identify the major barriers to a wider implementation of energy-efficient measures. Numerous authors such as Ahn and Pearce [20], Baek and Park [21], Issa et al. [22] and Thollander et al. [23] identified the initial costs of solutions as one of the biggest issues. The literature review performed within the European project Entranze (www. entranze.eu) reached the same outcome. Other studies [24-28] called attention to the lack of information on costs and benefits from stakeholders as another crucial aspect limiting their investment in energy-efficient measures. Thus, it is important to develop methods that promote the selection of not only cheaper but also more energy-efficient solutions than those selected through the CO method.

Other studies have been conducted with a view to analysing the costs and benefits of energy-efficient measures [29-31]. Nevertheless, these studies do not present a consistent method to select optimal solutions. As a result, some authors tried to develop several methods in order to analyse the economic viability of energy-efficient measures. Alajmi et al. [32] proposed the use of the Payback Period. Pal et al. [33] proposed the use of Life Cycle Costs (based on the Net Present Value approach). However, these approaches also prioritise the economic viability of solutions. Popescu et al. [34] concluded in their study that other parameters than the initial and operational costs should be considered in the analysis of energy-efficient measures. This is in line with the understanding that a building with energy-efficient measures has an added value, and therefore stakeholders may be more willing to pay for such measures. Banfi et al. [35] studied the consumers' willingness to pay for energy-saving measures in Switzerland's residential buildings. The results suggest that the benefits of energy-saving attributes are significantly valued by consumers.

In fact, a solution cannot be considered as economically viable if stakeholders are not willing to pay for it. Therefore, other studies have already been conducted in order to assess stakeholders' willingness to pay for sustainable solutions. Zalejska-Jonsson [36] analysed the rational willingness to pay for green apartments in Sweden. Dagher and Harajli [37], and Harajli and Gordon [38] analysed the willingness to pay for renewable-based electricity in Lebanon. Soon and Ahmad [39] developed a meta-analysis on the willingness to pay for renewable energy. Park et al. [40] analysed the willingness to pay for improvements in environmental performance of residential buildings. All in all, these studies succeeded in demonstrating the importance of taking into consideration stakeholders' willingness to pay for sustainable solutions. However, there is a lack of a comparative methodology that takes this parameter into account. Moreover, stakeholders' opinion on the process of comparing building solutions is important, because it leads to the selection of solutions that best suits their interests. Thus, this guarantees that the selected solution is in fact implemented in real-life situations [41]. This is very important since it bridges the gap between research and implementation.

The objective of this work is to develop and propose an alternative method to the $\mathrm{CO}$ method where the selection of the best building retrofitting solution is according not only to the LCC and energy performance of solutions, but also to stakeholders' desire/ willingness to invest in energy-efficient solutions. This will lead to a higher saving potential of EU's residential buildings, and consequently optimise the use of energy resources.

\section{Methodology}

The Cost-Benefit Analysis (CBA) method developed in this paper intends to compare different building solutions with regard to their costs and energy performance. The analysis of the economic performance of each solution is based on capital costs (regarding common market practices), operational costs and maintenance costs. The energy performance of each solution is assessed according to the method presented in ISO 13790 (ISO, 2008). Nevertheless, different methods are possible in order to assess the energy performance of buildings.

In order to develop the comparison and selection method, the CBA method was applied to a case-study building. Several energy-related building solutions were analysed and tested. Subsequently, the solutions were displayed in a graphical representation - similar to the one used in the CO method - and the comparison method was developed. Results and conclusions were drawn for each type of solution. Finally, a sensitivity analysis was performed to assess the robustness of the method in terms of energy prices and discount rate.

\section{Development of cost-benefit analysis method}

The CBA method enables the comparison between different building solutions within the context of refurbishment of a building. In order to compare solutions, a reference solution is considered. This reference solution is the existing or initially selected solution of the building, while other solutions are considered as alternatives. The CBA method is based on the cost and energy performance difference between each alternative and the reference solution.

\subsection{Assessment of life cycle costs}

As presented in Eq. (1), the building's LCC were assessed according to the method proposed in the European Commission Delegated Regulation No. 244/2012 of 16 January 2012 [12].

$C_{g}(\tau)=C_{I}+\sum_{j}\left[\sum_{i=1}^{\tau}\left(C_{a, i_{(j)}} \times R_{d}(i)-V_{f, \tau}(j)\right)\right]$

where:

$\tau$ - period;

$\mathrm{Cg}(\tau)$ - global cost over the calculation period;

$C_{I}$ - initial investment cost for the measure $j$;

$C_{a, I}(j)$ - annual cost during year $i$ for measure $j$;

$R_{d}(i)$ - discount rate for year $i$;

$V_{f, \tau}(j)$ - residual value of measure $j$ at the end of the calculation period.

A discount rate (inflation) of $3 \%$ was also taken into account, as well as the evolution in the energy costs. The energy prices predicted in EU energy trends to 2030, published by the European Commission in 2009, were considered for the period between 2013 and 2030 [42]. The prices forecasted in the Energy Road Map 2050 were used for the period between 2030 and 2043 [43].

Investment costs are estimated based on market analysis, and maintenance costs are calculated according to the required maintenance, and replacement costs if needed, for each type of solution.

\subsection{Assessment of energy performance}

The energy needs for heating and cooling are regulated according to certain comfort conditions (Summer Comfort Temperature: $25^{\circ} \mathrm{C}$ and Relative Humidity of 50\%; Winter Comfort Temperature: $20^{\circ} \mathrm{C}$ ), and based on building characteristics and location. 


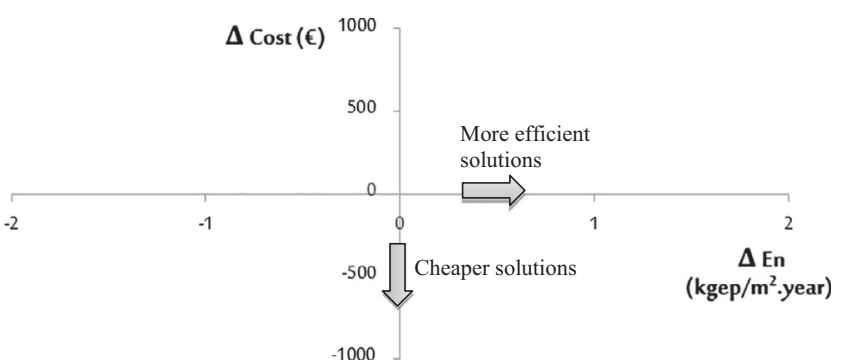

Fig. 2. Graphical representation of the Cost-Benefit Analysis method.

The calculations of heating and cooling needs were performed in accordance with the methodology included in the Portuguese thermal regulation, which is based on the quasi-steady state method presented in ISO 13790. The Portuguese thermal regulation provides the values of the degree-days and uses the envelope heat balance method for the calculation of heating needs. With regard to cooling needs, it uses the average difference between indoor-outdoor temperature and the envelope heat balance during the cooling period. The energy used for Domestic Hot Water (DHW) preparation is calculated according to the reference DHW consumption: $40 \mathrm{~L}$ per person and per day, heated at $60{ }^{\circ} \mathrm{C}$ [44].

The difference in life cycle energy performance is related to the difference in the building energy needs of each alternative solution when compared to the reference solution. Heating, cooling and DHW systems as well as the production of renewable energy, their service life and number of replacements needed over the 30 years of the building's life are accounted as maintenance costs.

\subsection{Cost-benefit analysis method - graphical schematisation}

The visualisation method uses a bi-dimensional graphical representation (Fig. 2). The vertical axis represents the cost variation, and the horizontal axis represents the energy performance variation. An alternative solution is always represented by a point in the graph. The reference solution is always represented by point $(0,0)$. The less expensive solutions will appear at the bottom in the graph, while the solutions with better energy performance will appear in the rightmost area of the graph.

In this study, the value of $\Delta E n$ and $\Delta$ Cost are calculated according to Eqs. (2) and (3), respectively.

$\Delta E n=E n_{r e f}-E n_{j}$

$\Delta \operatorname{Cost}=\operatorname{Cost}_{j}-\operatorname{Cost}_{r e f}$

where

$E n_{j}$ is the energy consumption of solution $j$;

$E n_{\text {ref }}$ is the energy consumption of the reference solution.

Cost $_{j}$ is the life cycle cost of solution $j$;

Cost $_{\text {ref }}$ is the life cycle cost of the reference solution.

This means that if the $\Delta E n$ value is positive, the solution is better than the reference solution as it consumes less energy. On the other hand, if the $\Delta E n$ value is negative, the solution consumes more energy, which means that it is worse than the reference solution. Moreover, if $\Delta$ Cost has a positive value, it means that the solution $j$ is worse as it is more expensive than the reference solution.

This method takes into consideration some important aspects when comparing solutions. When a solution is cheaper and has a better energy performance than others, it is easy to fall into the conclusion that it is better than the reference solution (in the graph it appears at the bottom right corner of the quadrant IV). However, when comparing alternatives in which one is more expensive but

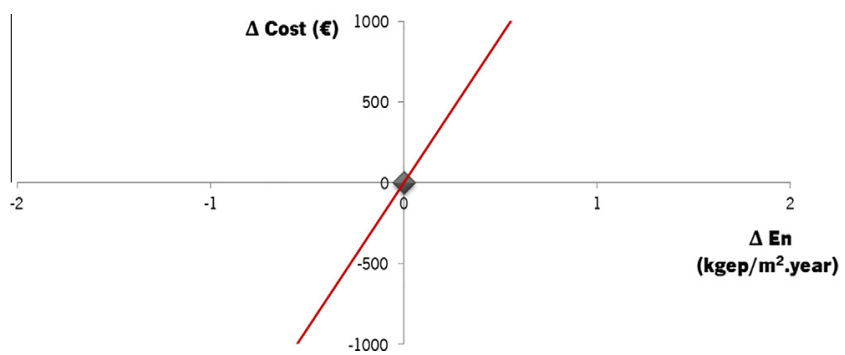

Fig. 3. Graphical representation of the value of money reference line.

has better energy performance than the other, such conclusions may not be so obvious. The solution to this problem lies in finding a comparison method that takes into account the value of money or the stakeholder's willingness to invest in expensive high performance solutions or in cheap low performance solutions. This comparison method is very important to provide an answer to the question: To what extent is someone willing to pay for a certain improvement in the energy performance of a building?

In numerical terms, this is the same as choosing an ideal costbenefit ratio for a certain budget. This ratio can be very different between stakeholders. In order to define this ratio, stakeholders' investment willingness should be analysed. The comparative line should be adapted to each stakeholder. This will allow not only the comparison of solutions but also the selection of the one that best suits each individual.

Taking into account that the willingness to invest in energyefficient measures can vary for different levels of investment or desired energy efficiency, the line can take a linear or non-linear shape.

In order to test this method's real application, this work uses a linear relationship based on what is considered economically viable in Portugal according to Decree Law 79/2006 [45]. This corresponds to a payback period of 8 years. The cost difference between two solutions ( $\Delta$ Cost) is related to the product between the annual energy needs variation $(\Delta E n)$ and the energy costs (Ecost). By considering the payback period of 8 years, a line can be drawn in the graph by using Eq. (4) that represents the value of money (Fig. 3).

$\Delta \operatorname{Cost}(j)=\Delta E n(j) \times A \times \sum_{i=1}^{P B} E \operatorname{cost}(i) \times R_{d}(i)$

where:

$\Delta E n$ - primary energy needs variation $\left(\mathrm{kW} \mathrm{h} / \mathrm{m}^{2}\right.$ year $)$;

$\Delta$ Cost - cost variation $(€)$;

$A$ - net area $\left(\mathrm{m}^{2}\right)$;

$P B$ - payback period (years);

Ecost $(i)$ - primary energy cost $(€ / \mathrm{kW} \mathrm{h})$;

$R_{d}(i)$ - discount rate for year $i$.

\subsection{Process for comparison and selection of solutions}

The payback period is a good indicator of the economic feasibility of a solution as it presents the length of time required for the investor to recover the invested value. However, it is not enough to adequately compare different solutions. For instance, if a solution presents a good payback period, this could mean that the solution has a good implementation potential. On the other hand, if its initial costs are higher than the amount the investor is able to invest, it will not be preferable. In fact, the EU's CO method selects the solution with the best payback period. This is equivalent to graphing a horizontal line that gives $100 \%$ weight to economic performance. 


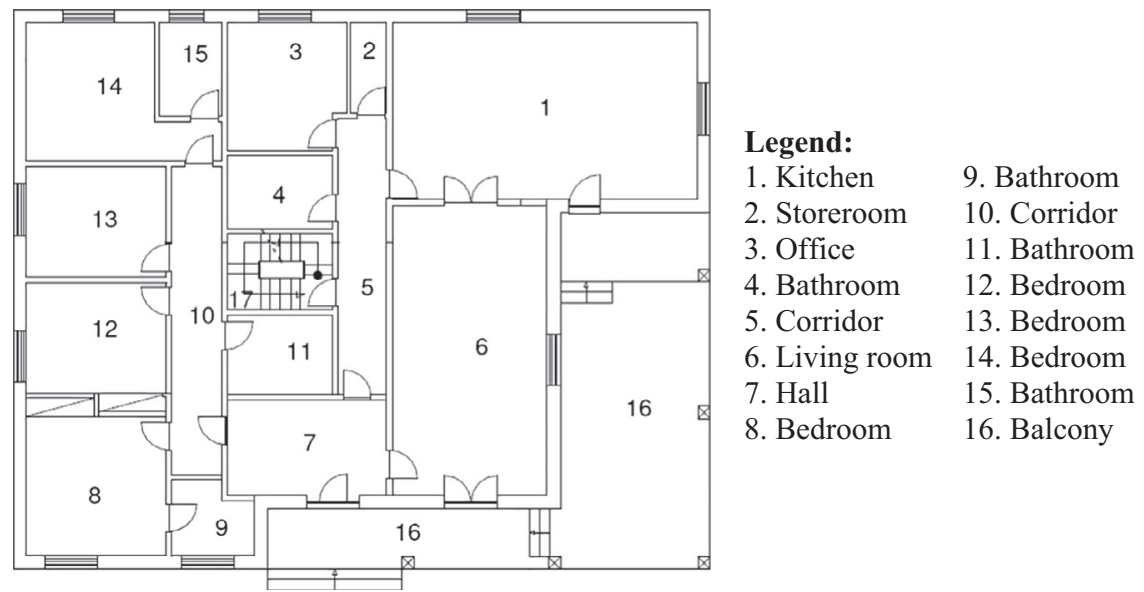

Fig. 4. Layout of the building's first floor.

Therefore, through the CBA method it is possible to compare solutions by taking into account an ideal relation between economic and energy performances (represented by the gradient of the reference line). Points positioned on top of a line parallel to the reference line will have exactly the same cost-benefit relation. After defining the gradient, solutions can be compared regarding their distance to the reference line. The lower and to the right a solution is located in relation to the reference line, the better its cost-benefit ratio will be.

The distance of a point to a line in a bi-dimensional graph is calculated by Eq. (5). This equation compares solutions by taking into account all intended variables.

$d_{P, S}=\left(a x_{0}+b y_{0}+c\right) /\left(\sqrt{a^{2}+b^{2}}\right)$

where

$d$ - distance from point $P$ to line $s$;

$a, b, c$ - coefficients of the line $s$ equation;

$x_{0}, y_{0}-$ coordinates of point $P$.

Thus, this distance represents the perpendicular distance between a point representing the (economic and energy) performance of each solution and the reference line. The best solution is the one with the greatest negative or smallest positive distance (d) to the reference line.

\section{Case study}

The case study (Fig. 4) is a four-room single-family detached house with a heated area of $271.6 \mathrm{~m}^{2}$. It is located in the North of Portugal at an altitude of $74 \mathrm{~m}$ and about $25 \mathrm{~km}$ from the Atlantic Ocean. According to the Portuguese legislation, the climatic region of this building is I2, V2 North (between the most severe, I3 V3, and the mildest, I1 V1, climatic regions) and its thermal inertia is classified as heavy.

This case study represents a significant number of buildings in Portugal. As presented in Fig. 5, Portugal has around 3,500,000 buildings and 5,700,000 dwellings, where the North stands out for having the largest portion (around 1,200,000 buildings and 1,800,000 dwellings). In Portugal, detached houses are very common, representing the most popular type of construction, and approximately $91 \%$ of the Portuguese buildings were architecturally developed to have 1 or 2 dwellings [46,47].

The DHW preparation system of the case study is a boiler. This system's efficiency could not be determined either in the visit to the building or by analysing the building's documents. In these cases, the Portuguese thermal regulation states the properties that should be assumed when performing energy calculations. For a gas boiler, an efficiency of $65 \%$ should be considered. With regard to the calculations for heating and cooling needs, the following systems were considered (common practice in Portuguese dwellings) [46].

- Heating system - an electrical resistance with a nominal efficiency of 1.

- Cooling system - a refrigerating device with a nominal efficiency of 3.

Fig. 6 presents a sectional view of the case-study building, showing the heated and non-heated areas. The heated area is the living area where the temperature should be controlled and kept

\section{BUILDING DISTRIBUTION}

\begin{tabular}{r|c} 
Portugal & 3543595 \\
North & 1209830 \\
Centre & 1111682 \\
Lisbon & 448720 \\
Alentejo & 383737 \\
Algarve & 198860 \\
Azores & 98807 \\
Madeira & 91959
\end{tabular}

\section{DWELLING DISTRIBUTION}

\begin{tabular}{r|c} 
Portugal & \\
North & 18638503 \\
Centre & 1448408 \\
Lisbon & 1487717 \\
Alentejo & 471628 \\
Algarve & 379937 \\
Azores & 109846 \\
Madeira & 129642
\end{tabular}

Fig. 5. Building and dwelling distribution according to geographic zones in Portugal. 


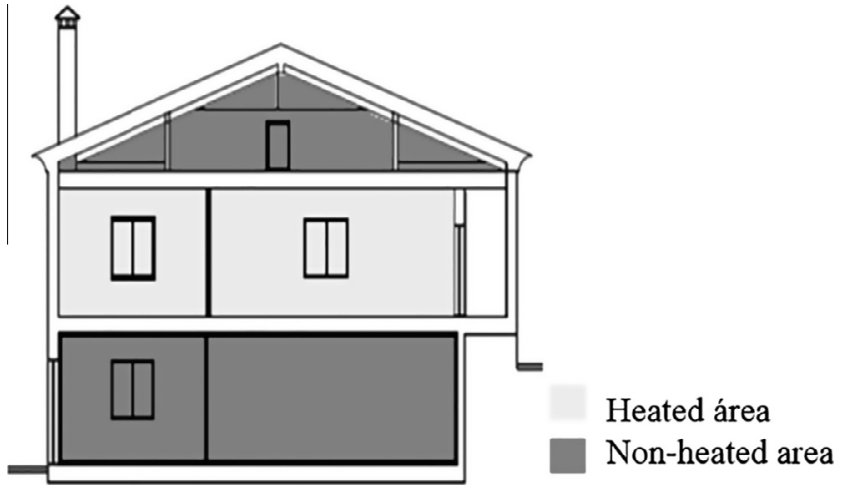

Fig. 6. Sectional view of the case-study building.

Table 1

Area and orientation of the building's elements.

\begin{tabular}{lcl}
\hline Element & Area $\left(\mathrm{m}^{2}\right)$ & Orientation \\
\hline External walls & 41.8 & North \\
& 29.5 & South \\
& 36.1 & East \\
Glazing & 44.9 & West \\
& 3.3 & North \\
& 6.1 & South \\
Roof & 3.3 & East \\
Floor & 7.7 & West \\
\end{tabular}

within the range of the comfort temperatures. The Portuguese thermal regulation defines the rules for identifying the heated and non-heated areas of buildings. As the ground floor and the loft are non-heated spaces, this study only takes into consideration the areas located in the first floor.

The building has double cavity external walls and single cavity internal walls. The roofs and floors are voided slabs and the windows are double glazed with metal frames. Table 1 presents the area and orientation of the elements of the building.

For the purpose of this work, some energy parameters were chosen in order to find energy-efficient solutions that are important in the calculation of the building's energy performance. In previous work, these parameters were considered the most influential parameters regarding the buildings' energy needs and energy rating in the Portuguese regulation [48].

The parameters chosen are the following: (1) the heat transfer coefficient $(U)$ of walls, roof, floor, surface thermal bridges and windows; (2) the number of air changes per hour (Rph); (3) the solar factor of windows $(g)$; (4) the shading factor $(F s)$ of vertical and horizontal windows; (5) the absorption factor of external walls $(\alpha)$; (6) the efficiency of the DHW preparation system ( $\eta a)$; (7) the contribution of solar systems to DHW preparation (energy supplied by the sun - Esolar); (8) the heating system efficiency ( $\eta i)$; and (9) the cooling system efficiency $(\eta v)$.

The solar factor of windows is the ratio between the solar energy transmitted through the window and the total solar radiation that hits the window [44]. In order to calculate this value, the existence of external and/or internal solar protection must be considered.

For each of the aforementioned parameters, alternative solutions to the conventional reference solutions existing in the building were investigated. The selected alternative solutions include at least one high-performance and one low-performance solution. Notwithstanding, all the selected solutions are used and marketed in Portugal, and were chosen because they represent the most common solutions used in the Portuguese single-family detached houses. In total, eighty-two different solutions were analysed.

The reference solutions for each of the aforementioned parameters are shown in Table 2.

The case-study building complies with all the legislative thermal requirements, and its energy label is B- (minimum allowed for new buildings).

\section{Discussion on the application of the cost-benefit analysis method}

The following chapters will present the application of the method to the solutions analysed under two of the aforementioned parameters: heat transfer coefficient of external walls (parameter 1.1) and heat transfer coefficient of floor slabs (parameter 1.2). These two parameters were chosen because their results draw on

Table 2

Case-study reference solutions.

\begin{tabular}{|c|c|c|c|}
\hline Parameter & & Solution & Value \\
\hline \multirow[t]{5}{*}{$\begin{array}{l}\text { 1. Heat transfer } \\
\text { coefficient }\end{array}$} & 1.1. External walls & $\begin{array}{l}\text { Double-leaf cavity wall }(15 \mathrm{~cm}+11 \mathrm{~cm}) \text { with } 4 \mathrm{~cm} \text { of extruded } \\
\text { polystyrene }\end{array}$ & $U=0.50 \mathrm{~W} / \mathrm{m}^{2}{ }^{\circ} \mathrm{C}$ \\
\hline & 1.2. Roof & Lightweight slab with $4 \mathrm{~cm}$ of extruded polystyrene & $U=0.50 \mathrm{~W} / \mathrm{m}^{2}{ }^{\circ} \mathrm{C}$ \\
\hline & 1.3. Floor & Lightweight slab with $4 \mathrm{~cm}$ of extruded polystyrene & $U=0.50 \mathrm{~W} / \mathrm{m}^{2}{ }^{\circ} \mathrm{C}$ \\
\hline & 1.4. Windows & Double glazing with metal frames & $U=3.10 \mathrm{~W} / \mathrm{m}^{2}{ }^{\circ} \mathrm{C}$ \\
\hline & 1.5. Surface thermal bridges & Reinforced concrete pillar with $3 \mathrm{~cm}$ of extruded polystyrene & $U=0.70 \mathrm{~W} / \mathrm{m}^{2}{ }^{\circ} \mathrm{C}$ \\
\hline \multicolumn{2}{|c|}{ 2. Indoor air changes rate ( $\mathrm{Rph})$} & Natural ventilation & $\mathrm{Rph}=0.95$ \\
\hline \multirow{3}{*}{$\begin{array}{l}\text { 3. Solar factor of } \\
\text { Windows }\end{array}$} & 3.1. Summer - glass type analysis & Colourless double glazing & $g=0.75$ \\
\hline & 3.2. Summer - external protection analysis & Window external protection - Wooden shutters & $g=0.46$ \\
\hline & 3.3. Winter & Window internal protection - Curtains & $g=0.63$ \\
\hline \multirow[t]{2}{*}{ 4. Shading factor } & $\begin{array}{l}\text { 4.1. Shading factor - Horizontal shading - } \\
\mathrm{Fo}^{\mathrm{a}}\end{array}$ & A horizontal shading element in two East-oriented windows & $\begin{array}{l}\text { Winter }- \text { Fo }=0.71 \\
\text { Summer }- \text { Fo }=0.61\end{array}$ \\
\hline & 4.2. Shading factor - Vertical shading - Ff & A vertical shading element in two East-oriented windows & $\begin{array}{l}\text { Winter }-\mathrm{Ff}=0.74 \\
\text { Summer }-\mathrm{Ff}=0.96\end{array}$ \\
\hline \multicolumn{2}{|c|}{ 5. Absorption factor of external walls $(\alpha)^{\mathrm{b}}$} & Colour of external walls - white & $\alpha=0.4$ \\
\hline \multicolumn{2}{|c|}{ 6. Efficiency of DHW preparation systems $(\eta a)$} & Boiler & $\eta a=0.65$ \\
\hline \multicolumn{2}{|c|}{ 7. Contribution of solar systems to DHW preparation (Esolar) ${ }^{c}$} & Solar collector (forced circulation system) & Esolar $=2153 \mathrm{~kW} \mathrm{~h}$ \\
\hline \multicolumn{2}{|c|}{ 8. Heating system efficiency $(\eta i)$} & Electrical resistance & $\mathrm{COP}=1$ \\
\hline \multicolumn{2}{|c|}{ 9. Cooling system efficiency $(\eta v)$} & Refrigerating device & $\mathrm{EER}=3$ \\
\hline
\end{tabular}

The shading factor represents the reduction of the solar radiation received by a window due to permanent shading devices (horizontal or vertical).

b The absorption factor represents the capacity of the external walls to absorb energy from solar radiation.

c Esolar is the quantity of energy (kW h) produced by solar systems for DHW preparation, calculated according to the Portuguese thermal regulation. 
Table 3

Alternative solutions to analyse the heat transfer coefficient of external walls.

\begin{tabular}{ll}
\hline Solution & $\begin{array}{l}U(\mathrm{~W} / \\
\left.\mathrm{m}^{2}{ }^{\circ} \mathrm{C}\right)\end{array}$ \\
\hline 1. Reference Solution: Double cavity wall $(15 \mathrm{~cm}+11 \mathrm{~cm})$ with & 0.50 \\
$4 \mathrm{~cm}$ of Extruded Polystyrene (XPS) & \\
1.1. Double-leaf cavity wall $(15 \mathrm{~cm}+11 \mathrm{~cm})$ with $3 \mathrm{~cm}$ of XPS & 0.58 \\
1.2. Double-leaf cavity wall $(15 \mathrm{~cm}+11 \mathrm{~cm})$ with $8 \mathrm{~cm}$ of XPS & 0.32 \\
1.3. Double-leaf cavity wall $(22 \mathrm{~cm}+22 \mathrm{~cm})$ with $8 \mathrm{~cm}$ of XPS & 0.28 \\
1.4. ETICS - single-leaf cavity wall $(15 \mathrm{~cm})$ with $4 \mathrm{~cm}$ XPS & 0.58 \\
1.5. ETICS - single-leaf cavity wall $(15 \mathrm{~cm})$ with $8 \mathrm{~cm}$ XPS & 0.35 \\
1.6. ETICS - single-leaf cavity wall $(22 \mathrm{~cm})$ with $8 \mathrm{~cm}$ XPS & 0.33 \\
\hline
\end{tabular}

important conclusions about the potential of the method, such as the influence of the capital costs versus operational costs, and the importance of the gradient of the reference line. The application of the method to other parameters showed similar results and analysis, and hence are omitted due to space constraints.

The value of initial costs and LCC have different weights to different stakeholders (a building user may be more interested in the operational costs and an investor may be more concerned with the initial costs). Therefore, the initial costs of each solution are also presented, although the CBA was based on LCC.

\subsection{Heat transfer coefficient of walls belonging to the exterior envelope}

The reduction of heat transfer through the building envelope is very important in order to achieve energy efficiency in buildings [49], as well as to prevent some building pathologies. The economic analysis performed for the parameter "Heat transfer coefficient of external walls" is presented below. The alternative solutions used to perform the analysis of this parameter are shown in Table 3. The characterisation and results of these solutions are shown in Table 4. Finally, Fig. 7 shows the graphical representation of the alternative solutions.

The values used in this analysis are shown in Table 4 . The initial and operational costs of each alternative solution are presented in the second and third columns. The LCC variation of each alternative solution compared to the reference solution is presented in the fifth column. The energy needs of each solution (En) are presented in the sixth column, and the variations of energy needs between the alternative solutions and the reference solutions $(\Delta E n)$ are shown in the seventh column. Finally, the distance between the point representative of each solution and the value of money reference line $(d)$ is presented in the last column. As explained before, the solutions with the best relation between energy and economic performance are those with the greatest negative or smallest positive distance $(d)$ to the reference line (Fig. 7).

The alternative solution with the best cost-benefit relation is Solution 1.3 as it presents the lowest value of $d(d=-7,66)$. Although this solution shows higher initial costs, its lower energy needs compensate for this value across its life cycle. Solution 1.1 presents lower initial costs than the reference solution, but leads towards higher energy needs, and thus has a worse cost-benefit relation. The analysis of this parameter shows that using an efficient solution for external walls can be a good investment, even if its initial price is higher.

\subsection{Heat transfer coefficient of roofs and floors}

The heat transfer coefficients of roofs and floors were studied according to the existing construction solution on the reference building. Four solutions were considered, three with different insulation thicknesses $(8 \mathrm{~cm}, 6 \mathrm{~cm}$ and $3 \mathrm{~cm}$ of XPS - Solutions 1.2.1, 1.2 .2 and 1.2 .3 , respectively). In the reference solution, the insulation is placed on the floor surface in contact with the heated spaces. However, this solution decreases the building thermal inertia. For this reason, an alternative solution with the insulation layer placed on the opposite surface of the floor was studied (Solution 1.2.4), and its advantages were verified (its energy and economic performance are better than the reference solution).

The economic analysis of this equipment is presented in Table 5 and Fig. 8.

However, Solution 1.2.1 presents the best relation between economic and energy performance (it shows the greatest negative

Table 4

Economic analysis of heat transfer coefficient of external walls.

\begin{tabular}{|c|c|c|c|c|c|c|c|}
\hline Solution & Initial costs $(€)$ & Operational costs $(€)$ & Life cycle cost $(€)$ & $\Delta \operatorname{Cost}(€)$ & 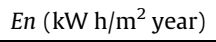 & $\Delta E n\left(\mathrm{~kW} \mathrm{~h} / \mathrm{m}^{2}\right.$ year $)$ & $d$ \\
\hline Solution 1 (reference) & 5189 & 73,521 & 7710 & 0 & 104.69 & 0 & 0.00 \\
\hline Solution 1.1 & 4863 & 75,105 & 79,968 & 1258 & 106.95 & 2.26 & 2.95 \\
\hline Solution 1.2 & 6349 & 69,967 & 76,316 & -2394 & 99.63 & -5.06 & -6.38 \\
\hline Solution 1.3 & 6860 & 69,178 & 76,039 & -2671 & 98.51 & -6.18 & -7.66 \\
\hline Solution 1.4 & 5755 & 75,105 & 80,861 & 2150 & 106.95 & 2.26 & 3.45 \\
\hline Solution 1.5 & 6193 & 70,557 & 76,750 & -1960 & 100.47 & -4.22 & -5.30 \\
\hline Solution 1.6 & 6690 & 70,166 & 76,856 & -1854 & 99.92 & -4.78 & -5.80 \\
\hline
\end{tabular}

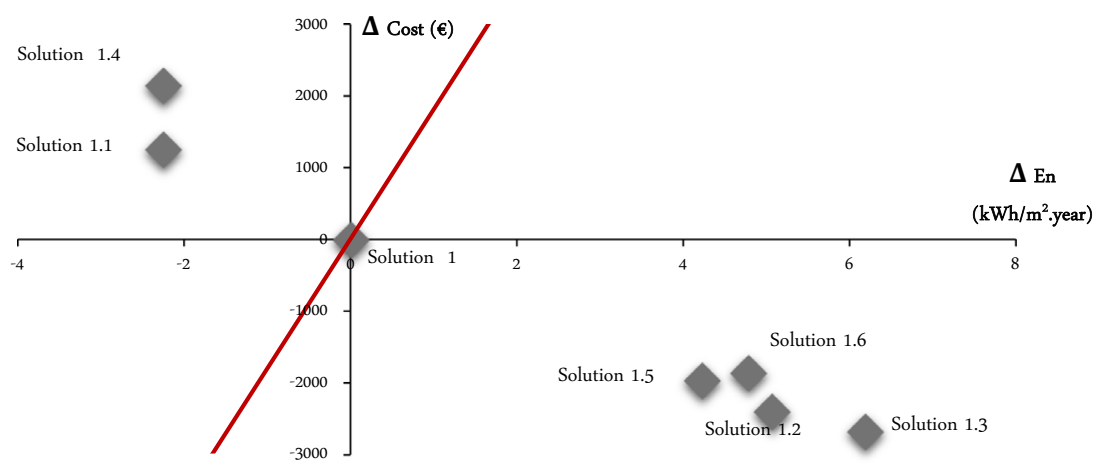

Fig. 7. Graphical representation of the economic analysis of heat transfer coefficient of external walls. 
Table 5

Economic analysis of heat transfer coefficient of roofs and floors.

\begin{tabular}{|c|c|c|c|c|c|c|c|}
\hline Solution & Initial costs $(€)$ & Operational costs $(€)$ & Life cycle cost $(€)$ & $\Delta \operatorname{Cost}(€)$ & En $\left(\mathrm{kW} \mathrm{h} / \mathrm{m}^{2}\right.$ year $)$ & $\Delta E n\left(\mathrm{~kW} \mathrm{~h} / \mathrm{m}^{2}\right.$ year $)$ & $d$ \\
\hline Solution 1.2 (reference) & 27,829 & 73,521 & 101350.1 & 0 & 104.7 & 0 & 0.00 \\
\hline Solution 1.2 .1 & 32,450 & 66,533 & 98983.3 & -2367 & 94.7 & 9.95 & -11.26 \\
\hline Solution 1.2 .2 & 29,640 & 69,399 & 99038.1 & -2312 & 98.8 & 5.87 & -7.15 \\
\hline Solution 1.2 .3 & 26,924 & 77,685 & 104609.3 & 3259 & 110.6 & -5.93 & 7.73 \\
\hline Solution 1.2 .4 & 27,829 & 70,585 & 98414.7 & -2935 & 100.5 & 4.18 & -5.80 \\
\hline
\end{tabular}

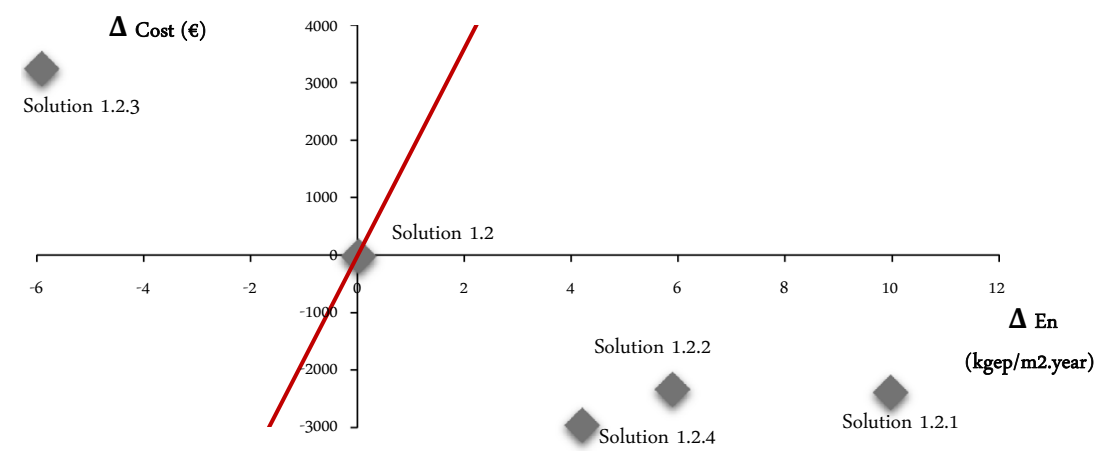

Fig. 8. Graphical representation of the economic analysis of heat transfer coefficient of roofs and floors.

distance to the reference line), although it is not the cheapest solution (Solution 1.2.4 is cheaper). Even though solution 1.2.1 presents higher costs, its energy performance makes it preferable to Solution 1.2.4 according to the CBA. Solutions 1.2.4 and 1.2.1 are very similar regarding their LCC. However, with a very low cost increase $(\sim 550 €)$, the building's energy performance can increase $4.2 \mathrm{~kW} \mathrm{~h} / \mathrm{m}^{2}$ year.

This example shows an added value of the CBA method: the possibility of choosing solutions that not only are more expensive than others but also have increased energy performance, making them more desirable.

\section{Sensitivity analysis}

In order to understand the consistency of the case-study results and its behaviour before different conditions, a sensitivity analysis was carried out. The analysis considers seven different scenarios, where the discount rate and the energy costs vary.

The European Commission Delegated Regulation No. 244/2012 of 16 January 2012 [12] states that when a CBA is performed a sensitivity analysis should also be developed with at least two different rates. In this sensitivity analysis, the following discount rates were considered: $1 \%, 2 \%, 4 \%, 5 \%$ and $6 \%$. Regarding the energy costs variation, an increase and decrease of $3 \%$ were analysed.

As an example, Table 6 presents the sensitivity analysis of the parameter "heat transfer coefficient of external walls". As explained before, the best solutions are those with the greatest negative distance to the reference line $(d)$.

The discount rate and energy price are factors with inverse impacts. The increase in the discount rate will decrease the value of money. Therefore, the solutions with low energy performance or high operational costs will be more advantageous as money will have a lower value. However, with an increase of the energy price, the same solutions will become less advantageous. This happens with Solutions 1.1 and 1.4 as these present higher energy needs than the reference solution, and an increase in energy price will make their operational costs also higher. Consequently, they will become more expensive in relation to the reference solution. On the other hand, Solutions 1.2, 1.3, 1.5 and 1.6, which present lower operational costs, become more advantageous with a decrease in the discount rate and an increase in the energy costs.

Regarding the other building solutions analysed, the same situation occurs. Some solutions become better and others become worse within the different scenarios. There are only two parameters in which the conclusions change in the scenarios analysed: the shading factor - vertical shading (parameter 4), and the heating systems (parameter 8). With regard to all the other parameters analysed, the variation on the discount rate and in the energy costs do not change the conclusions drawn by this study. The sensitivity analysis of the parameter "heating systems" is presented in Table 7.

The cost-benefit relation of Solution 8.3 is very similar to that of the reference solution. However, Solution 8.3 is more expensive (presenting higher initial and operational costs) while having

Table 6

Difference in the value of parameter " $d$ " for each solution within the different scenarios with regard to the heat transfer coefficient of external walls.

\begin{tabular}{|c|c|c|c|c|c|c|c|c|}
\hline & \multicolumn{8}{|c|}{$d$ (distance from each solution point to the reference line) } \\
\hline & \multicolumn{6}{|c|}{ Discount rate variation } & \multicolumn{2}{|c|}{ Energy price variation } \\
\hline & $1 \%$ & $2 \%$ & $3 \%$ & $4 \%$ & $5 \%$ & $6 \%$ & $-3 \%$ & $+3 \%$ \\
\hline Solution 1 & 0 & 0 & 0 & 0 & 0 & 0 & 0 & 0 \\
\hline Solution 1.1 & -3.157 & -3.047 & -2.953 & -2.872 & -2.801 & -2.740 & -2.949 & -2.956 \\
\hline Solution 1.2 & 6.864 & 6.607 & 6.385 & 6.192 & 6.024 & 5.875 & 6.368 & 6.400 \\
\hline Solution 1.3 & 8.259 & 7.939 & 7.661 & 7.420 & 7.207 & 7.019 & 7.636 & 7.685 \\
\hline Solution 1.4 & -3.609 & -3.520 & -3.447 & -3.387 & -3.339 & -3.300 & -3.459 & -3.435 \\
\hline Solution 1.5 & 5.706 & 5.491 & 5.305 & 5.143 & 5.002 & 4.877 & 5.290 & 5.318 \\
\hline Solution 1.6 & 6.274 & 6.022 & 5.803 & 5.611 & 5.442 & 5.291 & 5.779 & 5.824 \\
\hline
\end{tabular}


Table 7

Difference in the value of " $d$ " for each solution within the different scenarios with regard to heating systems.

\begin{tabular}{|c|c|c|c|c|c|c|c|c|}
\hline & \multicolumn{8}{|c|}{$d$ (distance from each solution point to the reference line) } \\
\hline & \multicolumn{6}{|c|}{ Discount rate variation } & \multicolumn{2}{|c|}{ Energy price variation } \\
\hline & $1 \%$ & $2 \%$ & $3 \%$ & $4 \%$ & $5 \%$ & $6 \%$ & $-3 \%$ & $+3 \%$ \\
\hline Solution 8 & 0 & 0 & 0 & 0 & 0 & 0 & 0 & 0 \\
\hline Solution 8.1 & 28.91 & 28.55 & 28.27 & 28.05 & 27.89 & 27.76 & 28.168 & 22.482 \\
\hline Solution 8.2 & 12.54 & 12.64 & 12.75 & 12.86 & 12.98 & 13.10 & 12.773 & 10.715 \\
\hline Solution 8.3 & 0.56 & 0.11 & -0.26 & -0.55 & -0.78 & -0.96 & -0.344 & -6.600 \\
\hline Solution 8.4 & -64.69 & -64.14 & -63.62 & -63.15 & -62.69 & -62.26 & -63.432 & -63.429 \\
\hline
\end{tabular}

lower energy needs. With an increase of the discount rate, the value of money decreases, and at some point (from $2 \%$ to $3 \%$ ) Solution 8.3 becomes slightly better than the reference solution.

Although there are some differences in the conclusions of some parameters, the sensitivity analysis shows that the results of the application of the CBA method to the case study present low sensitivity to the variation in the discount rate and energy costs. It is always important to perform a sensitivity analysis when applying this method in order to understand the robustness of the conclusions.

\section{Conclusions}

In this work, a method was developed to not only compare different energy-efficient solutions, regarding their economic and energy performance, but also select the optimal solution based on a cost-benefit ratio. This ratio can be translated into the slope of a reference line in a graphical display and represents the willingness of a particular stakeholder to invest in energy-efficient solutions. The method provided effective results in the comparison of different alternative solutions when applied to a case study. The bi-dimensional graphical analysis provides an easy and fast comparison between solutions. This helps stakeholders to easily compare building solutions and understand the benefits of their investment. The cost-benefit method leads to the selection of higher performance solutions with higher LCC, which are still desired by stakeholders. This shows an improvement regarding the CO method, which always selects the less expensive solution regardless of energy efficiency requirements oriented towards the achievement of EU 20-20-20 targets. Moreover, considering that the selection criteria is based on the investment willingness of stakeholders, this method can boost implementation of sustainable practices.

The cost-benefit method can be applied in the design phase of a new building or in a retrofitting operation with the objective of selecting the best solution or combination of solutions to improve energy efficiency. Thus, it can be used as a decision support tool with a view to helping designers select the solutions with the best equilibrium between technical and economic performance and the users/investors best interests.

The cost-benefit method can also be helpful in promoting a discussion about the less economic solutions, and whether some financial aid from government may be needed in certain situations. For instance, the application of this method can help identify some solutions with good energy performance and a prohibitive cost. This prohibitive situation is related to the stakeholder's investment availability. Therefore, it may be relevant to think about new programmes where some financial help may be given to stakeholders in order to promote the implementation of such solutions.

A sensitivity analysis regarding the variation of discount rate and energy costs was performed, and the case-study results showed they are not dependent on the variation of energy prices or discount rates. The results and conclusions from the analysis of building solutions (through the CBA method) do not change significantly with plausible variations of these variables. Moreover, since the discount rates and the calculation of energy prices were done using similar methods that were used in other methodologies, such as the EU's CO method, the problem related to bad forecast is common to all methodologies of the kind.

\section{Future developments}

The gradient of the reference line used to compare different solutions is the comparative base of the method developed, representing the willingness of a stakeholder to invest in building solutions. In the study, a payback period of 8 years was used to represent common Portuguese stakeholders. In future works, a more representative gradient for the value of money reference line will be developed for several types of stakeholders and regions through a campaign of questionnaires.

It is also worth mentioning that it is possible that the value of money reference line - establishing the relation between the importance of money and energy performance - is not completely linear. This means that the same stakeholder, while having preference for a determined payback period, has a different investment willingness regarding the LCC of building solutions. As a rule, it is easier to invest in cheaper solutions, even with longer payback periods, than in expensive solutions with shorter payback periods. Future works will study the possible non-linearity of the reference line. Moreover, the development of a 3D CBA regarding separately the initial and operational costs, and energy performance is predicted. This will possibly lead to a new comparison method based not only on the willingness to invest in energy-efficient solutions, but also on budget or investment availability.

Another future development will be the combination of energyefficient measures in the application of this method. This is particularly important because energy savings are different when measures are combined. Additionally, the combination of measures is more representative of the reality, as stakeholders' decisions are always simultaneously applied to all measures.

\section{References}

[1] EEA. Energy and non-energy related greenhouse gas emissions (ENER 001). Assessment published August 2011; 2011

[2] IPCC. Climate change. Synthesis report; 2007.

[3] EU. Directive 31/2010/EU of 19 May 2010 on the energy performance of buildings; 2010.

[4] Eurostat. Energy production and imports. Eurostat. Statistics Explained; 2014. <http://ec.europa.eu/eurostat/statistics-explained/index.php/Energy production_and_imports> [accessed: 09-November-2015].

[5] EC. Energy Efficiency Plan 2011, European Commission; 2011.

[6] EC. Action plan for energy efficiency: realising the potential. European Commission; 2006.

[7] Parameshwaran R, Kalaiselvam S, Harikrishnan S, Elayaperumal A. Sustainable thermal energy storage technologies for buildings: a review. Renew Sustain Energy Rev 2012:16:2394-433.

[8] EC. Europe 2020 targets. European Commission; 2015. <http://ec.europa.eu/ europe2020/europe-2020-in-a-nutshell/targets/index_en.htm> [accessed: 09November-2015].

[9] EC. 2030 climate and energy goals for a competitive, secure and low-carbon EU economy. European Commission; 2014. <http://europa.eu/rapid/pressrelease_IP-14-54_en.htm>. [accessed: 12-November-2015]. 
[10] European Climate Foundation. Roadmap 2050: a practical guide to a prosperous, low-carbon Europe; 2010. p. 99.

[11] EC. Directive 2002/91/EC of the European Parliament and of the council of 16 December 2002 on the energy performance of buildings. Offic J Eur Commun; 2002.

[12] EU. Commission Delegated Regulation (EU) no. 244/2012 of 16 January 2012. Offic J Eur Commun; 2012.

[13] Ferreira M, Almeida M, Rodrigues A. Cost optimality and net-zero energy in the renovation of Portuguese residential building stock - Rainha Dona Leonor neighbourhood case study. Int J Sustain Build Technol Urban Dev 2014.

[14] Congedo PM, Baglivo C, D’Agostino D, Zacà I. Cost-optimal design for nearly zero energy office buildings located in warm climates. Energy 2015;91 (November):967-82.

[15] Baglivo C, Congedo PM, D’Agostino D, Zacà I. Cost-optimal analysis and technical comparison between standard and high efficient mono-residential buildings in a warm climate. Energy 2015;83(April):560-75.

[16] Becchio C, Dabbene P, Fabrizio E, Monetti V, Filippi M. Cost optimality assessment of a single family house: building and technical systems solutions for the nZEB target. Energy Build 2015;90(March):173-87.

[17] Pikas E, Thalfeldt M, Kurnitski J. Cost optimal and nearly zero energy building solutions for office buildings. Energy Build 2014;74:30-42.

[18] Wesselink B, Harmsen R, Wolfgang E. Energy Savings 2020: How to triple the impact of energy saving policies in Europe - a contributing study to Roadmap 2050; 2010.

[19] Park JS, Lee SJ, Kim KH, Kwon KW, Jeong J-W. Estimating thermal performance and energy saving potential of residential buildings using Utility bills. Energy Build 2015;110(October):23-30.

[20] Ahn YH, Pearce AR. Green construction: contractor experiences, expectations, and perceptions. J Green Build 2007;2(October):106-22.

[21] Baek C, Park S. Policy measures to overcome barriers to energy renovation of existing buildings. Renew Sustain Energy Rev 2012;16(6):3939-47.

[22] Issa MH, Rankin JH, Christian AJ. Canadian practitioners' perception of research work investigating the cost premiums, long-term costs and health and productivity benefits of green buildings. Build Environ 2010;45:1698-711.

[23] Thollander P, Backlund S, Trianni A, Cagno E. Beyond barriers - a case study on driving forces for improved energy efficiency in the foundry industries in Finland, France, Germany, Italy, Poland, Spain, and Sweden. Appl Energy 2013;111(November):636-43.

[24] Cagno E, Trianni A, Abeelen C, Worrell E, Miggiano F. Barriers and drivers for energy efficiency: different perspectives from an exploratory study in the Netherlands. Energy Convers Manage 2015;102(April):26-38.

[25] Caputo P, Pasetti G. Overcoming the inertia of building energy retrofit at municipal level: the Italian challenge. Sustain Cities Soc 2015:15(July):120-34.

[26] Heiskanen E, Matschoss K, Kuusi H, Kranzl L, Lapillone B, Sebi C, et al. Working paper: literature review of key stakeholders, users and investors; 2012.

[27] Persson J, Grönkvist S. Drivers for and barriers to low-energy buildings in Sweden. J Clean Prod 2014(October).

[28] Balcombe P, Rigby D, Azapagic A. Investigating the importance of motivations and barriers related to microgeneration uptake in the UK. Appl Energy 2014;130(October):403-18.

[29] Stephan A, Stephan L. Life cycle energy and cost analysis of embodied, operational and user-transport energy reduction measures for residential buildings. Appl Energy 2016;161(January):445-64.
[30] Eicker U, Demir E, Gürlich D. Strategies for cost efficient refurbishment and solar energy integration in European Case Study buildings. Energy Build 2015;102(September):237-49.

[31] Romero Rodríguez L, Salmerón Lissén JM, Sánchez Ramos J, Rodríguez Jara EÁ, Álvarez Domínguez S. Analysis of the economic feasibility and reduction of a building's energy consumption and emissions when integrating hybrid solar thermal/PV/micro-CHP systems. Appl Energy 2016;165(March):828-38.

[32] AlAjmi A, Abou-Ziyan H, Ghoneim A. Achieving annual and monthly net-zero energy of existing building in hot climate. Appl Energy 2016;165 (March):511-21.

[33] Pal SK, Alanne K, Jokisalo J, Siren K. Energy performance and economic viability of advanced window technologies for a new Finnish townhouse concept. Appl Energy 2016;162(January):11-20.

[34] Popescu D, Bienert S, Schützenhofer C, Boazu R. Impact of energy efficiency measures on the economic value of buildings. Appl Energy 2012:89:454-63.

[35] Banfi S, Farsi M, Filippini M, Jakob M. Willingness to pay for energy-saving measures in residential buildings. Energy Econ 2008;30(2):503-16.

[36] Zalejska-Jonsson A. Stated WTP and rational WTP: willingness to pay for green apartments in Sweden. Sustain Cities Soc 2014;13(October):46-56.

[37] Dagher L, Harajli H. Willingness to pay for green power in an unreliable electricity sector: Part 1 . The case of the Lebanese residential sector. Renew Sustain Energy Rev 2015;50(October):1634-42.

[38] Harajli H, Gordon F. Willingness to pay for green power in an unreliable electricity sector: Part 2. The case of the Lebanese commercial sector. Renew Sustain Energy Rev 2015;50(October):1643-9.

[39] Soon J-J, Ahmad S-A. Willingly or grudgingly? A meta-analysis on the willingness-to-pay for renewable energy use. Renew Sustain Energy Rev 2015;44(April):877-87.

[40] Park M, Hagishima A, Tanimoto J, Chun C. Willingness to pay for improvements in environmental performance of residential buildings. Build Environ 2013;60(February):225-33.

[41] Nishida Y, Hua Y. Motivating stakeholders to deliver change: Tokyo's cap-andtrade program. Build Res Inf 2011:39(November):518-33.

[42] EC. EU Energy Trends to 2030 - Update 2009. European Commission. Directorate-General for Energy; 2009.

[43] EC. Communication from the commission to the European Parliament, the council, the European economic and social committee and the committee of the regions. Energy Roadmap 2050. European Commission; 2011.

[44] Portugal. Decreto-Lei no 80/2006 - Regulamento das Características de Comportamento Térmico de Edifícios. Diário da República - I Série-A, no. 67, 4 Abril 2006.

[45] Portugal. Decreto-Lei no79/2006 - Regulamento dos Sistemas Energéticos e de Climatização de Edifícios, Diário da República - I Série - A, no. 67, 4 Abril 2006.

[46] Healy JD. Housing conditions, energy efficiency, affordability and satisfaction with housing: a pan European analysis. Dublin: University College Dublin; 2002.

[47] INE. CENSUS 2011 - Resultados Provisórios, vol. 2013. Instituto Nacional de Estatística; 2011

[48] Araújo C, Almeida M, Bragança L. Analysis of some Portuguese thermal regulation parameters. Energy Build 2013;58:141-50.

[49] Pilkington B, Grove S. Thermal conductivity probe length to radius ratio problem when measuring building insulation materials. Constr Build Mater 2012;35:531-46 